\title{
Expression of Fas and Fas ligand in human gastric adenomas and intestinal-type carcinomas: correlation with proliferation and apoptosis
}

\author{
Mitsuhiko Osaki, Satoru Kase, Isamu Kodani, Mari Watanabe, Hironobu Adachi, and Hisao Ito \\ First Department of Pathology, Faculty of Medicine, Tottori University, 86 Nishi-cho, Yonago, Tottori 683-8503, Japan
}

\begin{abstract}
Background. Fas (APO-1/CD95), a member of the tumor necrosis factor/nerve growth factor receptor superfamily, mediates apoptosis in response to agonistic antibodies or Fas ligand (FasL) binding. Previous reports indicated an upregulation of FasL in gastric carcinomas to evade host immune attack. Fas/FasL expression, however, has not been analyzed in terms of apoptosis and proliferation in gastric adenoma and carcinoma.

Methods. This study was conducted on seven human gastric carcinoma cell lines, 47 gastric adenomas, and 75 intestinaltype adenocarcinomas (48 early and 27 advanced carcinomas). Fas/FasL expression was examined by immunohistochemistry, apoptosis by the terminal deoxynucleotidyl transferasemediated dUTP-digoxigenin nick-end labeling (TUNEL) method, and Fas gene mutation by a reverse transcriptase (RT) polymerase chain reaction-single-strand conformation polymorphism (PCR-SSCP) and sequencing method.

Results. Fas and FasL expressions were noted in 18 (38.3\%) and $17(36.2 \%)$ adenomas, in $21(43.8 \%)$ and $33(68.8 \%)$ early carcinomas, and in $10(37.0 \%)$ and $19(70.4 \%)$ advanced carcinomas, respectively. The frequency of FasL expression was significantly higher in advanced carcinomas than in the early carcinomas and adenomas; in contrast, there was no significant difference in Fas expression among the three groups. The mean apoptotic index (AI) was $4.96 \pm 0.51$ in the adenomas, $2.96 \pm 0.23$ in the early carcinomas, and $1.67 \pm 0.17$ in the advanced carcinomas. A significantly higher AI was noted in the lesions with Fas expression than in those without Fas expression in all three groups. No missense mutations of the Fas gene were detected in any of the gastric carcinoma cell lines, or in the gastric adenomas or carcinomas.

Conclusions. Upregulation of FasL may correlate with the progression of gastric carcinoma. Apoptosis in gastric adenoma and carcinoma cells may occur via Fas-dependent and -independent pathways, but further clarification is needed.
\end{abstract}

Offprint requests to: $\mathrm{M}$. Osaki

Received: August 6, 2001 / Accepted: October 3, 2001
Key words Fas · Fas ligand · Gastric carcinoma - Apoptosis · Fas gene mutation

\section{Introduction}

Apoptosis is a distinct form of cell death, distinguishable from necrosis by morphology, biochemistry, and molecular biology. Apoptosis is a basic biological phenomenon that is of crucial importance in the regulation of cell populations in situations as diverse as metamorphosis, embryogenesis and modeling, hormone-induced organ involution, and neoplasia. Recent studies have analyzed tumor development and progression in terms of proliferation and apoptotic cell death (cell loss) in a variety of human malignancies, including gastric carcinoma.

Our previous studies showed that apoptosis was variably detected in human gastric adenoma and carcinoma cells. The findings are summarized as follows: (i) a higher apoptotic index (AI; percentage of apoptotic tumor cells) in tubular adenomas, followed by welldifferentiated (intestinal-type), and poorly differentiated (diffuse-type) carcinomas [1-3], (ii) lower AI in carcinomas expressing P53 oncoprotein $[3,4]$, (iii) increase in AI with preoperative chemotherapy [5], (iv) association of thymidine phosphorylase expression with lower AI [6], and (v) an inverse correlation between AI and intratumoral microvessel density (IMVD) [6]. Thus, apoptosis is correlated with tumor histology, p53 gene status, and cytotoxic agents such as anticancer agents, as well as being correlated with blood supply. These findings suggest the presence of variable pathways of signal transduction that may exert a wide spectrum of biologic effects, depending on the apoptosisinducible factors that are present.

The Fas-Fas ligand (FasL) system has been recognized as the major pathway for the induction of 
apoptosis in a variety of human normal and neoplastic cells [7]. Fas antigen is a $45-\mathrm{kD}$ a cell-surface protein that belongs to the death receptor subfamily of the tumor necrosis factor/nerve growth factor receptor superfamily. Fas contains a unique cytoplasmic region, termed the "death domain", which is essential for the initiation of a cytolytic response [8]. The binding of Fas ligand (FasL) to Fas antigen results in the transduction of a cytolytic signal into the cell, followed by apoptosis, a process that has been well studied, mainly in hematopoietic cells $[9,10]$.

Alterations in the expression of Fas and FasL have been demonstrated in a variety of tumor cells. To date, several studies have demonstrated downregulation of Fas in a number of human malignant solid tumors, including esophageal [11] and breast [12] carcinomas. On the other hand, upregulation of FasL has been reported in various human malignant solid tumors, including hepatocellular [13], colon [14], lung [15], and pancreatic [16] carcinomas, as well as breast carcinomas [17]. Bennett et al. [18] reported a relationship between the upregulation of FasL and apoptosis in tumor-infiltrating lymphocytes (TILs) in gastric carcinoma. Moreover, $\mathrm{Li}$ et al. [19] have reported Fas and FasL expression in gastric cancer and its preneoplastic lesions in a small number of cases. However, there have been no studies that analyzed the relationship between Fas/FasL expression and apoptosis in gastric carcinoma cells.

In this study, we examined the expression of Fas and FasL in human gastric adenomas and carcinomas, as well as in seven human gastric carcinoma cell lines, relative to tumor cell apoptosis. We also analyzed Fas gene alterations to clarify the significance of Fas/FasL in the progression of human gastric adenomas and carcinomas.

\section{Materials and methods}

\section{Gastric carcinoma cell lines}

Table 1 shows the histological types and $p 53$ gene status of the seven cell lines derived from human gastric carcinomas analyzed in this study. All the cell lines were

Table 1. Human gastric cancer cell lines

\begin{tabular}{lll}
\hline Cell line & \multicolumn{1}{c}{ Histology } & \multicolumn{1}{c}{$p 53$ status } \\
\hline MKN-1 & Adenosquamous & Mutated \\
MKN-7 & Well-differentiated & Mutated \\
MKN-28 & Well-differentiated & Mutated \\
MKN-45 & Poorly differentiated & Wild type \\
MKN-74 & Well-differentiated & Wild type \\
TMK-1 & Poorly differentiated & Mutated \\
KATO-III & Signet-ring cell & Complete deletion \\
\hline
\end{tabular}

cultured in RPMI 1640 supplemented with $10 \%$ fetal calf serum (FCS), $100 \mathrm{U} / \mathrm{ml}$ penicillin, $100 \mu \mathrm{g} / \mathrm{ml}$ streptomycin, and $292 \mu \mathrm{g} / \mathrm{ml} \mathrm{L-glutamine}$ at $37^{\circ} \mathrm{C}$ in $5 \% \mathrm{CO}_{2}$.

\section{Tissue specimens}

Studies were conducted on 47 adenomas, obtained by endoscopic mucosal resection; and 75 surgically removed adenocarcinomas (48 early and 27 advanced carcinomas). The histological type of the gastric carcinomas in all cases was papillary and tubular adenocarcinoma, according to the criteria of the Japanese Gastric Cancer Association [20]. All the specimens were taken from the files of the Department of Pathology, Faculty of Medicine, Tottori University, and its related teaching hospitals. Routinely processed, formalin-fixed, paraffinembedded tissue blocks from the principal infiltration of the tumoral mass were selected. Three-micrometerthick sections were examined by light microscopy, immunohistochemistry, and the terminal deoxynucleotidyl transferase (TdT)-mediated dUTP-digoxigenin nickend labeling (TUNEL) procedure.

\section{Sodium dodecylsulfate-polyacrylamide gel electrophoresis (SDS-PAGE) and Western blot analysis}

SDS-PAGE and Western blot analysis were performed as described previously [21]. To evaluate the specificity of antibodies against human Fas and FasL, one polyclonal and two monoclonal anti-Fas antibodies and one polyclonal and three monoclonal anti-FasL antibodies were used. We selected the antibodies most specific to each of Fas and FasL. The membranes were blotted with nondiluted anti-Fas polyclonal antibody (Nichirei, Tokyo, Japan), which recognized the carboxy terminus of Fas protein, and a 1:1000 dilution of the antiFasL monoclonal antibody (mAb 33; Transduction Laboratories, Lexington, KY, USA), which recognized the carboxy terminus of FasL protein. Blots were developed with a second peroxidase-labeled antibody overnight at $4{ }^{\circ} \mathrm{C}$. After extensive washing had been done, specific bands were detected, using an enhanced chemiluminescence system (ECL Detection System; Amersham Pharmacia Biotech, Amersham, UK).

\section{Immunohistochemistry}

Dewaxed paraffin sections were immunostained, using the streptavidin-biotin peroxidase complex (SAB) method. The following primary antibodies were used: rabbit polyclonal antibody against Fas (Nichirei), and mouse monoclonal antibody against FasL (mAb33; diluted 1:400; Transduction Laboratories). Immunoreactions were visualized with diaminobenzidine 
(DAB), and the sections were counterstained with $3 \%$ methylgreen.

We judged samples to be positive for Fas or FasL when at least $20 \%$ of the tumor cells showed positive immunoreactivity.

\section{TUNEL method}

To detect DNA breaks in situ, TUNEL was performed according to the method of Gavrieli et al. [22], using an Apop Tag Plus in-situ apoptosis detection kit (Intergen, Purchase, NY, USA). Details of the method were described previously [6].

To examine the specificity of the TUNEL procedure, slides were treated with TdT buffer solution not containing TdT or digoxigenin-11-dNTP, as negative controls; these were invariably negative for TUNEL signals. The TUNEL procedure was also conducted at the same time on control slides of gastric carcinomas, which were previously shown to have many apoptotic cells with TUNEL signals, to obtain consistent findings.

\section{Statistical analyses}

Differences in numerical data values between two or three groups were evaluated using the Kruskal-Wallis test (Fas and FasL expression) and the Mann-Whitney $U$-test (AI). The level of significance was set at $P<0.05$.

Fas gene mutation of coding regions in gastric cancer cell lines

Fas gene mutations of coding regions were examined in all seven of the gastric carcinoma cell lines. Total RNA was isolated and cDNA synthesis was performed as described previously [23]. The primers used in this study and the polymerase chain reaction (PCR) procedure used have been described previously [24] except that no radioisotope was used in the PCR. All PCR products were analyzed by direct sequencing, using a Big Dye Terminator Cycle Sequencing kit (Amersham Pharmacia Biotech).

\section{Fas gene mutations in gastric adenomas} and carcinomas

Fas gene mutations were examined in 20 of the 47 gastric adenomas and in 30 of the 75 carcinomas in the paraffin-embedded blocks. Several $20-\mu \mathrm{m}$ sections were trimmed with a clean razor and placed in a $1.5-\mathrm{ml}$ tube. To avoid contamination, the microtome blade was removed and cleaned with xylene after use with each block. Genomic DNA was extracted using DEXPAT (TaKaRa, Kyoto, Japan). PCR primers were synthesized based on the Fas DNA sequences in exons 6 and 9, which encode the transmembrane domain and death domain, respectively. The sequences of the primer pairs were: $5^{\prime}$-tttcatataatatgccaatgttcc-3' and $5^{\prime}$-cttcccccaag ttatttcaat-3' for Fas exon 6; 5' -tgctggagtcatgacactaagt-3' and $5^{\prime}$-caatgtgtcatacgcttctttc- $3^{\prime}$ for Fas exon 9A; 5'taattggcatcaacttcat- $3^{\prime}$ and $5^{\prime}$-gaatttgttgtttttcactcta- $3^{\prime}$ for Fas exon 9B; and 5'-ggttttcactaatgggaatttcat-3' and 5'cttcattgacaccattctttcg-3' for Fas exon 9C [25-28]. Exon 9 was divided into three fragments. A single-strand conformation polymorphism (SSCP) method was performed by a standard procedure [29]. All cases in which abnormal band(s) were detected by SSCP were analyzed by direct sequencing, as described above.

\section{Results}

\section{Expression of Fas and FasL in human gastric} carcinoma cell lines

First, to test the specificity of the three different commercially available anti-Fas antibodies and the four anti-FasL antibodies, Western blot analysis was performed on the seven human gastric carcinoma cell lines. The anti-Fas rabbit polyclonal antibody purchased from Nichirei and the anti-FasL mouse monoclonal antibody (clone 33) purchased from Transduction Laboratories gave almost identical results in all cell lines. On the other hand, the other antibodies gave rise to a faint or non-specific labeling by Western blotting.

Next, we examined the expression levels of Fas and FasL by Western blot analysis. As shown in Fig. 1, both Fas and FasL proteins in the gastric carcinoma cell lines were detected specifically by the antibodies. Fas and FasL antigen were variably expressed in all seven cell lines examined, although there was extremely low expression in $\mathrm{MKN}-28$.

\section{Fas and FasL expression in human gastric adenoma and adenocarcinoma}

Fas antigen immunoreactivity was observed both on cell membranes and in the cytoplasm of adenoma and carci-

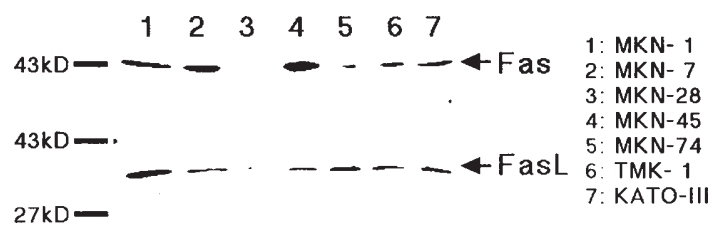

Fig. 1. Expression of Fas and FasL in seven gastric carcinoma cell lines, detected by Western blotting 


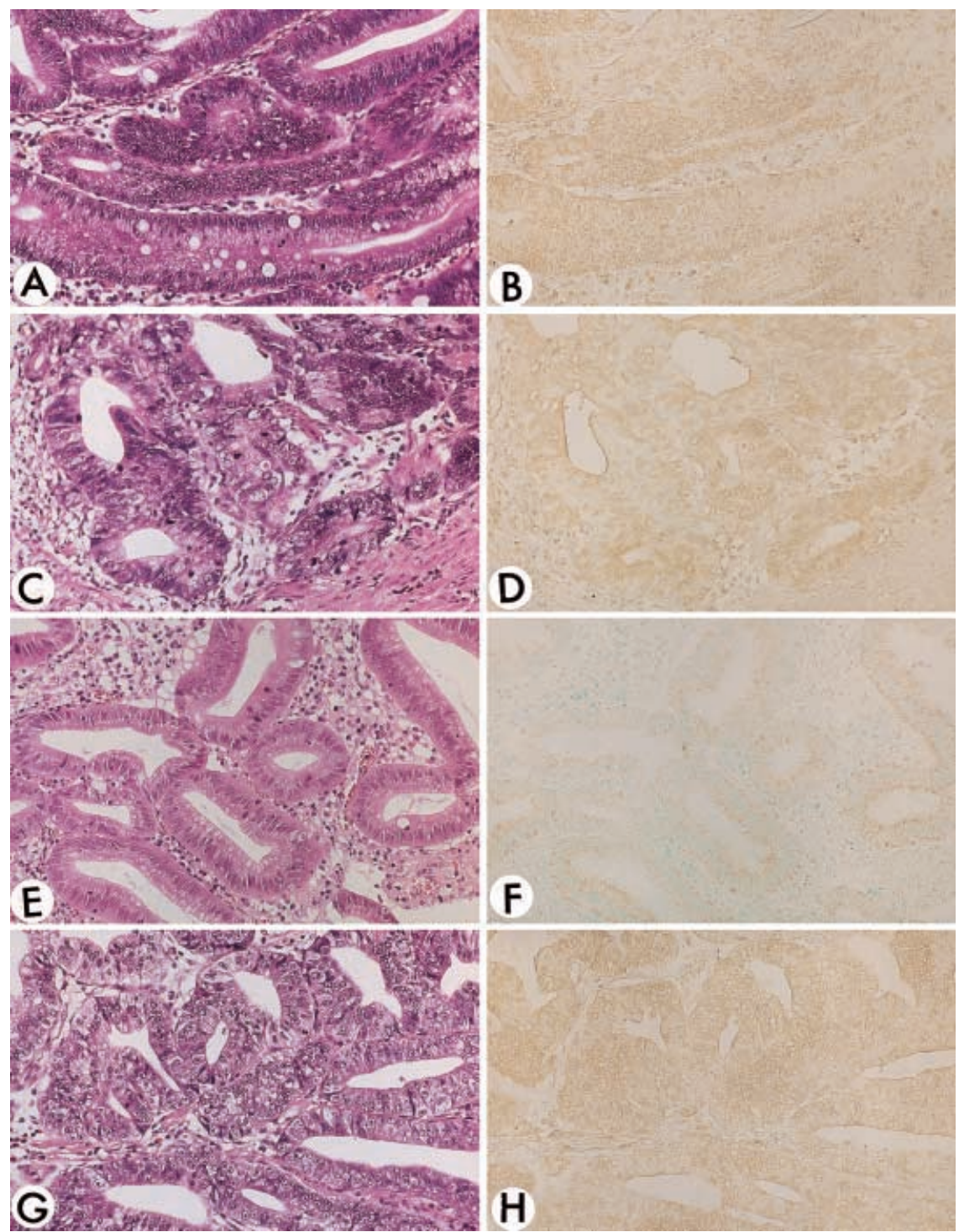

Fig. 2A-H. Fas and FasL expression in gastric adenoma and adenocarcinoma. Detection of Fas (B and D) and FasL (F and $\mathbf{H}$ ) expression by immunohistochemistry in gastric adenoma ( $\mathbf{B}$ and $\mathbf{F})$ and adenocarcinoma (D and $\mathbf{H})$. $\mathbf{A}, \mathbf{C}, \mathbf{E}$, and $\mathbf{G}$ are serial or semi-serial sections of $\mathbf{B}$, $\mathbf{D}, \mathbf{F}$, and $\mathbf{H}$, respectively. Fas expression is predominant in the cytoplasm rather than on cell membranes. On the other hand, FasL expression is predominant on cell membranes and is higher in adenocarcinoma than in adenoma. $\mathbf{A}, \mathbf{C}, \mathbf{E}$, and $\mathbf{G}$ : $\mathrm{H} \& \mathrm{E}, \times 140 ; \mathbf{B}, \mathbf{D}, \mathbf{F}$, and $\mathbf{H}$ : immunohistochemistry, $\times 140$ noma cells, being predominant in the cytoplasm (Fig. $2 \mathrm{~A}-\mathrm{D})$. Fas antigen expression was noted in $18(38.3 \%)$ of the 47 gastric adenomas, in $21(43.8 \%)$ of the 48 early carcinomas, and in $10(37.0 \%)$ of the 27 advanced carcinomas, the frequency showing no significant differences among the three categories (Table 2).

FasL immunoreactivity was observed both on cell membranes and in the cytoplasm of the adenoma and carcinoma cells. In contrast to Fas antigen, immunoreactivity was predominant on the cell membrane (Fig. 2E-H). FasL expression was noted in 17 (36.2\%) of the 47 gastric adenomas, in $33(68.8 \%)$ of the 48 early carcinomas and in $19(70.4 \%)$ of the 27 advanced carcinomas. The frequency of FasL-positive cases was significantly higher in advanced carcinomas than in early carcinomas and adenomas $(P<0.01$; Table 2$)$.

\section{Correlation between AI and Fas/FasL expression in gastric adenomas and adenocarcinomas}

With the TUNEL method, apoptotic tumor cells were clearly identified by brown nuclear signals (Fig. 3). Table 2 shows the correlations between $\mathrm{AI}$ and the three lesion categories. The mean AI was $4.96 \pm 0.51$ in the gastric adenomas, $2.96 \pm 0.23$ in the early carcinomas, and 1.67 \pm 0.17 in the advanced carcinomas. The mean AI was significantly higher in the adenomas than in both the early and the advanced carcinomas $(P<0.01)$.

Next, we analyzed mean AI relative to Fas and FasL expression (Table 3). The mean AI was significantly higher in the Fas-positive lesions than in the Fasnegative lesions in the adenomas $(6.93 \pm 1.03$ versus $3.86 \pm 0.42 ; P=0.015)$, the early carcinomas $(3.80 \pm$ 
Table 2. Expression of Fas/FasL and apoptotic index (AI)

\begin{tabular}{|c|c|c|c|c|c|}
\hline & \multicolumn{2}{|l|}{ Fas } & \multicolumn{2}{|l|}{ FasL } & \multirow[b]{2}{*}{$\mathrm{AI}($ mean $\pm \mathrm{SD})$} \\
\hline & + & - & + & - & \\
\hline Adenoma $(n=47)$ & $18(38.3 \%)$ & 29 & $17(36.2 \%)$ & 30 & $4.96 \pm 0.517$ \\
\hline \multicolumn{6}{|l|}{ Carcinoma } \\
\hline Early $(n=48)$ & $21(43.8 \%)$ & 27 & $33(68.8 \%)$ & 15 & $2.96 \pm 0.23 \overline{7} *$ \\
\hline Advanced $(n=27)$ & $10(37.0 \%)$ & 17 & $19(70.4 \%)$ & 8 & $1.67 \pm 0.17\rfloor *\rfloor$ \\
\hline
\end{tabular}

* $P<0.01$; The frequency of FasL expression was significantly higher in the carcinomas than in the adenomas $(P<0.01)$, but there was no significant difference between FasL expression in the early and advanced carcinomas

+ , positive case; - , negative case

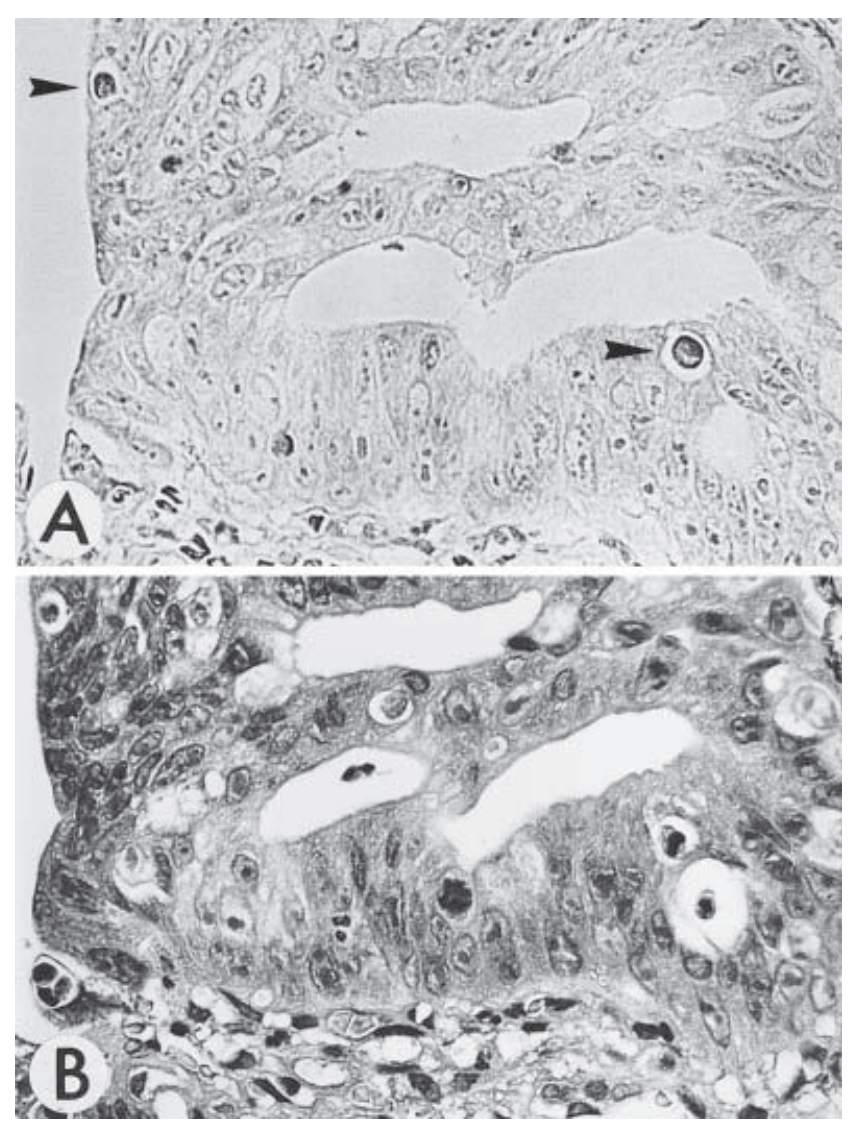

Fig. 3. Terminal deoxynucleotidyl transferase (TdT)mediated dUTP-digoxigenin nick-end labeling (TUNEL)signal-positive tumor cells are indicated by arrowheads. A TUNEL method; B H\&E, $\times 300$

0.36 versus $2.30 \pm 0.23 ; P=0.002)$, and the advanced carcinomas $(2.30 \pm 0.23$ versus $1.31 \pm 0.17 ; P=0.003)$. FasL expression, however, was not correlated with the $\mathrm{AI}$ in any of the three categories.

\section{Fas gene mutation}

Fas gene mutation was tested in the seven human gastric carcinoma cell lines, and in 20 gastric adenomas and
30 gastric carcinomas. We first analyzed the mRNA transcripts of the Fas gene by reverse transcriptase (RT)-PCR. As shown in Fig. 4, four pairs of primers were used to amplify four overlapping regions of Fas cDNA (fragments A, B, C, and D), which covered the entire coding region of Fas, along with part of the $5^{\prime}$ and $3^{\prime}$ untranslated regions of Fas cDNA. The 3' primer for fragment $\mathrm{B}$ and the $5^{\prime}$ primer for fragment $\mathrm{C}$ were designed to localize to the transmembrane domain of the Fas gene. The 3' primer for fragment $\mathrm{C}$ and the 5' primer for fragment $\mathrm{D}$ were designed to localize to the death domain of the Fas gene. Single specific bands were detected by RT-PCR in four fragments of the seven gastric carcinoma cell lines. Abnormal bands that suggested spliced mutants were not detected. All fragments were subsequently analyzed by direct sequencing to detect point mutations. However, no mutations of the Fas gene transcripts were detected in any of the cell lines.

We also examined point mutations of the Fas gene in the tissue specimens. None of the gastric adenoma samples showed mutations of the gene by SSCP analysis. An abnormal band was detected in one of 30 gastric carcinomas (CTT to CTA at codon 306 in exon 9; data not shown). Direct sequence analysis, however, showed it to be a silent mutation (Leu to Leu).

\section{Discussion}

In this study, we have clearly demonstrated both Fas and FasL expression in human gastric adenomas and intestinal-type carcinomas. In contrast to Fas expression, FasL expression has been shown to be restricted to a few cells or tissues, such as cytotoxic T lymphocytes (CTLs), Sertoli cells, and corneal epithelia, the latter two being immunologically privileged sites, which are able to evade a rejection reaction [30,31]. As alluded to in the "Introduction" [13-18], FasL expression has been analyzed in a variety of human malignancies, with results suggesting that tumor cells with FasL alterations 
Table 3. Relationship between Fas/FasL expression and AI

\begin{tabular}{|c|c|c|c|c|c|}
\hline \multirow{3}{*}{ Adenoma } & \multicolumn{2}{|c|}{$\begin{array}{l}\text { Fas/FasL } \\
\text { expression }\end{array}$} & \multirow{2}{*}{$\begin{array}{c}\begin{array}{c}\text { Number of } \\
\text { lesions }\end{array} \\
18\end{array}$} & \multicolumn{2}{|c|}{$\begin{array}{c}\text { AI } \\
(\text { mean } \pm S D)\end{array}$} \\
\hline & Fas & + & & $6.93 \pm 1.03$ & \\
\hline & & - & 29 & $3.86 \pm 0.42$ & $P=0.015$ \\
\hline & FasL & + & 17 & $5.44 \pm 0.81$ & \\
\hline & & - & 30 & $4.69 \pm 0.66$ & NS \\
\hline \multicolumn{6}{|l|}{ Carcinoma } \\
\hline \multirow[t]{4}{*}{ Early } & Fas & + & 21 & $3.80 \pm 0.36$ & \\
\hline & & - & 27 & $2.30 \pm 0.23$ & $P=0.002$ \\
\hline & FasL & + & 33 & $2.76 \pm 0.25$ & \\
\hline & & - & 15 & $3.40 \pm 0.48$ & NS \\
\hline \multirow[t]{4}{*}{ Advanced } & Fas & + & 10 & $2.30 \pm 0.23$ & \\
\hline & & - & 17 & $1.31 \pm 0.17$ & $P=0.003$ \\
\hline & FasL & + & 19 & $1.77 \pm 0.18$ & NS \\
\hline & & - & 8 & $1.45 \pm 0.36$ & NS \\
\hline
\end{tabular}

NS, Not significant

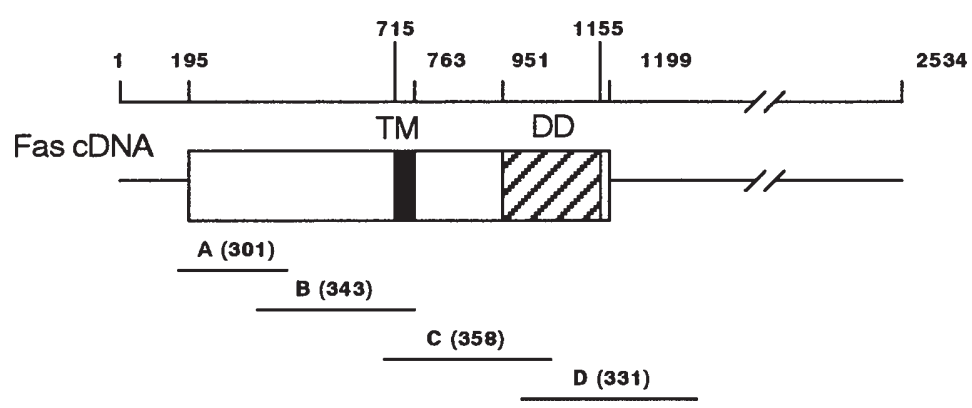

Fig. 4. Schematic presentation of Fas cDNA and the primer designed for reverse transcriptase-polymerase chain reactionsingle-strand conformation polymorphism (RT-PCR-SSCP) analysis. Nucleotide numbers are shown at the top. The 5'- and $3^{\prime}$ - untranslated regions of the cDNA are indicated by a single line. The coding regions, which are boxed, consist of the transmembrane domain $(T M)$ and the death domain $(D D)$. The sizes (in base pairs) of the products (fragments A, B, C, and D) are shown in parentheses

may evade host immunological attack by CTLs. This hypothesis has been questioned, however, because the specificity of the antibodies used had not been confirmed [32]. In this study, importantly, the specificity of the commercially available antibodies for Fas and FasL was confirmed. Western blot analysis showed that only one antibody for Fas or FasL detected single bands of about 45 and $37 \mathrm{kDa}$, corresponding to Fas and FasL, respectively. Moreover, Fas and FasL expressions were variable among the human gastric carcinoma cell lines we tested, and minimal expression of Fas was noted in MKN-28, which has been shown to be resistant to antiFas antibody-induced apoptosis [21]. Thus, it is unequivocal that Fas and FasL are expressed in human gastric tumors, although their actual roles and biological significance are largely unknown.

Of interest is the finding that the frequency of FasL expression was significantly higher in the carcinomas than in the adenomas, while no significant difference was noted in FasL expression between the early and advanced carcinomas. On the other hand, Fas expression did not differ among the three categories. These findings suggest that FasL is related to the carcinogenesis of gastric adenomas and the progression of intestinal-type gastric carcinomas. Moreover, the higher expression of FasL could provide a preferential advantage for tumor progression by allowing the tumor to evade immunological attack by CTLs, or, in other words, by killing the activated Fas-sensitive tumor infiltrating lymphocytes (TILs), as has been demonstrated in malignancies in other organs, including colon and pancreatic carcinomas [33,34].

We also analyzed the significance of Fas/FasL expression in terms of tumor cell apoptosis. The AI was highest in the adenomas, followed by the early carcinomas and advanced carcinomas. This finding supports those 
of our previous studies [1-3], in which we confirmed that apoptosis occurred predominantly via a $p 53$ geneindependent pathway in human gastric carcinomas. In the present study, we found that positivity for Fas expression in tumors correlated with a significantly higher AI in all three categories, in contrast to a finding of no association between FasL expression and AI. These findings provide further evidence that Fas expression may play a role in tumor cell proliferation in human gastric adenomas and carcinomas. Moreover, there may be some mechanism(s) for the evasion of Fas-mediated apoptosis in gastric carcinomas, as indicated by the significantly lower AI in the early and advanced carcinomas than in the adenomas, and the lack of difference in the frequency of Fas expression among the three groups.

Recently, somatic mutations of the Fas gene have been demonstrated in a variety of human malignancies (including lymphomas [35-37]), as well as in various solid tumors (including gastric carcinoma [25-28,38]). Park et al. [27] detected missense mutations in the death domain of the Fas gene in 5 (11.6\%) of 43 gastric carcinomas. In the present study, we investigated whether there were alterations in the Fas gene in seven gastric carcinoma cell lines, 20 gastric adenomas, and 30 gastric carcinomas, targeting exons 6 and 9, which encode the transmembrane domain and the death domain of Fas, respectively $[39,40]$, and which are known to show mutations more frequently than other exons [25-28,38]. However, no mutations were detected in any samples, except for one gastric carcinoma that showed a silent mutation (Leu-to-Leu). This different finding in our study may be partly explained by differences in the methods used in our study and that of Park et al. [27], who extracted genomic DNA from microdissected tissue specimens, whereas our extracted samples included DNA not only from carcinoma cells but also from other nontumorous cells, such as lymphocytes and endothelial cells.

In any case, the frequency of Fas gene mutation seems to be very low, and, thus, the lower AI in gastric carcinomas than in adenomas cannot be explained by mutations alone. Moreover, these findings suggest that gastric carcinomas possess other possible mechanism(s) of evading Fas-mediated apoptosis. The evasion of molecules related to Fas-mediated signal transduction is needed to account for the lower AI in gastric carcinomas. A few reports have noted that resistance to antiFas antibody-induced apoptosis may be correlated with caspase-8 downregulation in neuroblastoma, renal cell carcinoma, pancreatic carcinoma, and human monocytes [41-44]. This downregulation is associated with caspase- 8 gene silencing through DNA methylation and cFLIP upregulation, which inhibits the activation of caspase-8 [44].
In summary, we have demonstrated Fas/FasL expression in human gastric adenomas and carcinomas. FasL may be correlated with the progression of gastric carcinoma by a mechanism that involves the evasion of TILinduced apoptosis. On the other hand, Fas expression clearly resulted in increased apoptosis in adenoma and carcinoma cells. Thus, the Fas/FasL system seems to be relevant to the proliferation of gastric cancer cells.

Acknowledgments This work was supported, in part, by a Grant-in-Aid for Scientific Research from the Ministry of Education, Culture, Sports, Science, and Technology of Japan (grant number, 11470050). The authors thank Mr. N. Itaki and Ms M. Kajimura for their skillful technical assistance.

\section{References}

1. Ishida M, Gomyo Y, Tatebe S, Ohfuji S, Ito H. Apoptosis in human gastric mucosa, chronic gastritis, dysplasia and carcinoma: analysis by terminal deoxynucleotidyl transferase-mediated dUTP-biotin nick end labeling. Virchows Arch 1996;428:22935.

2. Ohfuji S, Osaki M, Tsujitani S, Ikeguchi M, Sairenji T, Ito H. Low frequency of apoptosis in Epstein-Barr virus-associated gastric carcinoma with lymphoid stroma. Int J Cancer 1996;68:710-5.

3. Ikeda M, Shomori K, Endo K, Makino T, Matsuura T, Ito H. Frequent occurrence of apoptosis is an early event in the oncogenesis of human gastric carcinoma. Virchows Arch 1998;432:437.

4. Ishida M, Gomyo Y, Ohfuji S, Ikeda M, Kawasaki H, Ito H. Evidence that expression of a mutated p53 gene attenuates apoptotic cell death in human gastric intestinal-type carcinomas in vivo. Int J Cancer 1997;88:468-75.

5. Sugamura K, Makino M, Shirai H, Kimura O, Maeta M, Ito H, et al. Enhanced induction of apoptosis of human gastric carcinoma cells after preoperative treatment with 5-fluorouracil. Cancer 1997;79:12-70.

6. Osaki M, Sakatani T, Okamoto E, Goto E, Adachi H, Ito H. Thymidine phosphorylase expression results in a decrease in apoptosis and increase in intratumoral microvessel density in human gastric carcinomas. Virchows Arch 2000;437:31-6.

7. Nagata S. Apoptosis by death factor. Cell 1996;88:355-65.

8. Nagata S, Golstein P. The Fas death factor. Science 1995;267: $1449-56$.

9. Muzio M, Chinnaiyan AM, Kischkel FC, O'Rourke K, Shevchenko A, Ni J, et al. FLICE, a novel FADD-homologous ICE/CED-3-like protease, is recruited to the CD95(FAS/APO-1) death-inducing signaling complex. Cell 1996;85:817-27.

10. Peter ME, Krammer PH. Mechanism of CD95 (APO-1/Fas)mediated apoptosis. Curr Opin Immunol 1998;10:545-51.

11. Gratas C, Tohma Y, Barnas C, Taniere P, Hainaut P, Ohgaki H. Up-regulation of Fas (APO-1/CD95) ligand and down-regulation of Fas expression in human esophageal cancer. Cancer Res 1998;58:2057-62.

12. Mottolese M, Buglioni S, Bracalenti C, Andrea C, Ciabocco L, Giannarelli D, et al. Prognostic relevance of altered Fas (CD95)system in human breast cancer. Int J Cancer (Pred Oncol) 2000;89:127-32.

13. Higaki K, Yano H, Kojiro M. Fas antigen expression and its relationship with apoptosis in human hepatocellular carcinoma and noncancerous tissues. Am J Pathol 1996;149:429-37.

14. Moller P, Koretz K, Leithauser F, Bruderlein S, Henne C, Quentmeier A, et al. Expression of APO-1 (CD95), a member of 
the NGF/TNF receptor superfamily, in normal and neoplastic colon epithelium. Int J Cancer 1994;57:371-7.

15. Niehans GA, Brunner T, Frizelle SP, Liston JC, Salerno CT, Knapp DJ, et al. Human lung carcinomas express Fas ligand. Cancer Res 1997;57:1007-12.

16. Ungefroren H, Voss M, Jansen M, Roeder C, Hanne-Bruns D, Kremer B, et al. Human pancreatic adenocarcinomas express Fas and Fas ligand yet are resistant to Fas-mediated apoptosis. Cancer Res 1998;58:1741-9.

17. Mullauer L, IMosberger I, Grusch M, Rudas M, Chott A. Fas ligand is expressed in normal breast epithelial cells and is frequently up-regulated in breast cancer. J Pathol 2000;190:20-30.

18. Bennett MW, O'Connell J, O'Sullivan C, Roche D, Brady C, Kelly J, et al. Expression of Fas ligand by human gastric adenocarcinomas: a potential mechanism of immune escape in stomach cancer. Gut 1999;44:156-62.

19. Li H, Liu N, Guo L, Li JW, Liu J. Frequent expression of soluble Fas and Fas ligand in Chinese stomach cancer and its preneoplastic lesions. Int J Mol Med 2000;5:473-6.

20. Japanese Gastric Cancer Association. Japanese classification of gastric carcinoma. 2nd English ed. Tokyo: Kanehara; 1998.

21. Hayashi H, Tatebe S, Osaki M, Goto A, Suzuki Y, Ito H. Expression of Fas antigen and its mediation of apoptosis in human gastric cancer cell lines. Jpn J Cancer Res 1997;88:49-55.

22. Gavrieli Y, Sherman Y, Ben-Sasson SA. Identification of programmed cell death in situ via specific labeling of nuclear DNA fragmentation. J Cell Biol 1992;119:493-501.

23. Hayashi H, Tatebe S, Osaki M, Goto A, Sato K, Ito H. Anti-Fas antibody-induced apoptosis in human colorectal carcinoma cell lines: role of the $p 53$ gene. Apoptosis 1998;3:431-7.

24. Horiuchi T, Nishizaka H, Yasunaga S, Higuchi M, Tsukamoto H, Hayashi K, et al. Association of Fas/APO-1 gene polymorphism with systemic lupus erythematosus in Japanese. Rheumatology 1999;38:516-20.

25. Lee SH, Shin MS, Kim HS, Park WS, Kim SY, Jang JJ, et al. Somatic mutation of Fas (Apo-1/CD95) gene in cutaneous squamous cell carcinoma arising from a burn scar. J Invest Dermatol 1999;114:122-6.

26. Lee SH, Shin MS, Park WS, Kim SY, Kim HS, Han JY, et al. Alteration of Fas (Apo-1/CD95) gene in non-small cell lung cancer. Oncogene 1999;18:3754-60.

27. Park SW, Oh RR, Kim YS, Park JY, Lee SH, Shin MS, et al. Somatic mutations in the death domain of the Fas (Apo-1/CD95) gene in gastric cancer. J Pathol 2001;193:162-8.

28. Shin MS, Park WS, Kim SY, Kim HS, Kang SJ, Song KY, et al. Alteration of Fas (Apo-1/CD95) gene in cutaneous malignant melanoma. Am J Pathol 1999;154:1785-91.

29. Gomyo Y, Osaki M, Kaibara N, Ito H. Numerical aberration and point mutation of $p 53$ gene in human gastric intestinal metaplasia and well-differentiated adenocarcinoma: analysis by fluorescence in situ hybridization (FISH) and PCR-SSCP. Int J Cancer 1996; 66:594-9.
30. Lee J, Richburg JH, Younkin SC, Boekelheide K. The Fas system is a key regulator of germ cell apoptosis in the testis. Endocrinology 1997;138:2081-8.

31. Griffith TS, Yu X, Herndon JM, Green DR, Ferguson TA. CD95induced apoptosis of lymphocytes in an immune privileged site induces immunological tolerance. Immunity 1996;5:7-16.

32. Baker JR Jr, Bretz JD. Specificity questions concerning the clone 33 anti-fas ligand antibody. Cell Death Differ 2000;7:8-9.

33. O'Connell J, O'Sullivan GC, Collins JK, Shanahan F. The Fas counter attack: Fas-mediated T cell killing by colon cancer cells expressing Fas ligand. J Exp Med 1996;184:1075-82.

33. Elnemr A, Ohta T, Yachine A, Kayahara M, Kitagawa H, Ninimiya I, et al. Human pancreatic cancer cells express nonfunctional Fas receptors and counterattack lymphocytes by expressing Fas ligand; a potential mechanism for immune escape. Int J Oncol 2001;18:33-9.

34. Gronbaek K, Straten PT, Ralfkiaer E, Ahrenkiel V, Andersen MK, Hansen NE. Somatic Fas mutations in non-Hodgkin's lymphoma: association with extra nodal disease and autoimmunity. Blood 1998;92:3018-24

35. Beltinger C, Kurz E, Bohler T, Schrappe M, Ludwig W-D, Debatin KM. CD95 (APO-1/Fas) mutations in childhood Tlineage acute lymphoblastic leukemia. Blood 1998;91:3943-51.

36. Beltinger C, Bohler T, Karawajew L, Ludwig W-D, Schrappe M, Debatin KM. Mutation analysis of CD95 (Apo-1/Fas) in childhood B-lineage acute lymphoblastic leukemia. $\mathrm{Br} \mathrm{J}$ Haematol 1998;102:722-8.

37. Takayama H, Takakuwa T, Dong Z, Nonomura N, Okuyama A, Nagata $\mathrm{S}$, et al. Fas gene mutations in prostatic intraepithelial neoplasia and concurrent carcinoma: analysis of laser capture microdissected specimens. Lab Invest 2001;81:283-8.

38. Cheng J, Liu C, Koopman WJ, Mountz JD. Characterization of human Fas gene. J Immunol 1995;154:1239-45.

39. Behrmann I, Walczak H, Krammer PH. Structure of the human APO-1 gene. J Immunol 1994;24:3057-62.

40. Teitz T, Wei T, Valentine MB, Vanin EF, Grenet J, Valentine VA, et al. Caspase 8 is deleted or silenced preferentially in childhood neuroblastomas with amplification of MYCN. Nature Med 2000;6:529-35.

41. Kolenko V, Uzzo RG, Bukowski R, Bander NH, Novick AC, Hsi $\mathrm{ED}$, et al. Dead or dying: necrosis versus apoptosis in caspasedeficient human renal cell carcinoma. Cancer Res 1999;59:283842.

42. Perera LP, Waldmann TA. Activation of human monocytes induces caspase-8/FLICE. Proc Natl Acad Sci USA 1998;95:1430813 .

43. Elnemr A, Ohta T, Yachie A, Kayahara M, Kitagawa H, Fujimura T, et al. Human pancreatic cancer cells disable function of Fas receptors at several levels in Fas signal transduction pathway. Int J Oncol 2001;18:311-6.

44. Irmler M, Thome M, Hahne M, Schneider P, Hofmann K, Steiner $\mathrm{V}$, et al. Inhibition of death receptor signals by cellular FLIP. Nature 1997;388:190-5. 